\title{
An Ideal yet Highly Accurate Model Correlating Global Average Temperature to Excess $\mathrm{CO}_{2}$-Emissions
}

\author{
Roland H. Pawelke
}

\begin{abstract}
The causality of preceding atmospheric excess-to-equilibrium $\mathrm{CO}_{2}$-amounts and trailing system temperature increase is captured in terms of the ideal gas law, equilibrium thermodynamics and transition state theory for the first time: the model's performance is excellent, publicly available global mean temperature data from $1880\left(13.58^{\circ} \mathrm{C} / 290.7 \mathrm{ppm}\right)$ to April $2021\left(14.49^{\circ} \mathrm{C} / 416.2 \mathrm{ppm}\right)$ are reproduced at less than $\pm 2 \%$ deviation. Eight future global mean temperatures for atmospheric $\mathrm{CO}_{2}$-levels between $450 \mathrm{ppm}$ and $7000 \mathrm{ppm}$ are extrapolated and an empiric expression of the relation is derived. The model's ideal nature allows adaption for other greenhouse gases and provides a reference for conclusions about the energetic weighting and the wider significance of the $\mathrm{CO}_{2}$-based proportion in the total Greenhouse effect.
\end{abstract}

\section{Introduction}

Global climate change and the Greenhouse effect need no particular introduction for being items of extensive academic, educational and media coverage; yet the principal dispute about the existence of anthropogenic climate change, which seemingly never truly resolved nor passed over the years, makes for an interesting point transcending divisive debate: If the matter were clearly accountable on a generally accepted objective basis, the dispute could have hardly materialized or would have quickly resolved by argument. The mere fact that the dispute came into existence, dragging-on at varying intensity, tells of much more than the absence of a common ground for discussion.

Rather surprisingly, reviewing relevant literature suggests the apparent fact that the causality of anthropogenic $\mathrm{CO}_{2}$-emissions and global warming has never been demonstrated in a compellingly simple yet comprehensive fundamental way, which is as befitting as hard to believe: there are socalled simple models but these do not abide well enough by this standard. ${ }^{1}$ However, the subject fulfils all vital premises towards that end: first, atmospheric carbon dioxide concentrations figure by the hundreds of parts per million which equals partial pressures in the order of magnitude of $10^{-4}$ bar, at sub-per mille bar pressures even the exemplary real gas carbon dioxide may be considered as ideal. Second, the relation of atmospheric $\mathrm{CO}_{2}$-concentration to the remainder natural carbon cycle is essentially an equilibrium one. Third, the anthropogenic Greenhouse effect bases (largely, as theory has it) on excess-to-equilibrium $\mathrm{CO}_{2}$-amounts and the frequencies of its well-known IR-active vibrational modes. Hence the problem is of ideal-fundamental character and completely defined; the above considerations apply by principle to any other greenhouse gas, too.

Capturing $\mathrm{CO}_{2}$-Greenhouse effect causality for the first time on basis of these fundamentals, starting from clear premises, following a transparent line of argument and arriving at definite results, is the mission of this paper.

\section{Methodical approach}

The line of argument rests on the following premises: a) there is a distinct atmospheric $\mathrm{CO}_{2}$-level corresponding to a certain global mean temperature, the relation is elastic to some extent but ultimately bears the traits of a static equilibrium between carbon dioxide emitters and absorbers; $b$ ) said equilibrium may be disturbed by an external $\mathrm{CO}_{2}$-amount, over-saturating absorber capacity and 
leading to an increased atmospheric concentration; $c$ ) the Greenhouse effect materializes from the IR-active molecular vibrations of that excess-to-equilibrium $\mathrm{CO}_{2}$-amount.

Since carbon dioxide is a trace gas in the atmosphere, accounting for a partial pressure in the order of magnitude of $10^{-4}$ bar, its contextual behaviour can be well-approximated by the ideal gas law. The temperature-dependent equilibrium between atmospheric $\mathrm{CO}_{2}$-level and natural absorbers can be thus captured in terms of the van't Hoff equation, relating the chemical potential of the ideal gas with the $2^{\text {nd }}$ law of thermodynamics, as shown in equation 1 for desorption $\left(\Delta H_{m}{ }^{\circ}>0\right)$.

$\ln \left(\frac{p_{\mathrm{eq}}}{\mathrm{p}^{\circ}}\right)=\frac{-\Delta H_{\mathrm{m}}^{\circ}}{\mathrm{R} T}+\frac{\Delta S_{\mathrm{m}}^{\circ}}{\mathrm{R}} \quad \Rightarrow \quad-\mathrm{R} T \ln \left(\frac{p_{\mathrm{eq}}}{\mathrm{p}^{\circ}}\right)=\Delta H_{\mathrm{m}}^{\circ}-T \Delta S_{\mathrm{m}}^{\circ}=\Delta G_{\mathrm{m}}^{\circ}$

The notion of an ideal global equilibrium pressure is accountable enough but the mere idea of attempting to numerically determine the manifold land- respective sea-bound mass transfer $\mathrm{CO}_{2}-$ equilibria for the global sorption reaction parameters $\Delta H_{\mathrm{m}}{ }^{\circ}$ and $\Delta S_{\mathrm{m}}{ }^{\circ}$ appears absurd. Opting for a fundamental solution is preferable and the conception of a baseline $\mathrm{CO}_{2}$-threshold translating to equilibrium pressure $p_{\text {eq }}$ and global warming at pressures $p_{\text {eq }}{ }^{*}$ above it suffices towards that end.

Such excess-to-baseline system pressures $p_{\text {eq }}{ }^{*}$ are still indexed as equilibrium pressures because a priority of an excess $\mathrm{CO}_{2}$-amount does not necessarily entail a thermal runaway logic, on the contrary: Warming represents in this context the system's reaction to an equilibrium disturbance in the gas phase which cannot be mitigated by mass transfer towards the absorbers. Yet by equilibrium thermodynamics, a preceding higher atmospheric $\mathrm{CO}_{2}$-concetration entails a latency period in which no further mass transfer from the baseline $p_{\text {eq }}$ equilibrium system into the gas phase can occur until heating raises temperature from $T$ to $T^{*}$ for an equilibrium pressure equal to the now applying $\mathrm{CO}_{2}-$ partial pressure $p_{\mathrm{eq}}{ }^{*}$. Only beyond that point may further heating cause mass transfer from the baseline $p_{\text {eq }}$ system into the atmosphere. By principle, this gives the Greenhouse effect a stairwaylike structure but continuous excess emissions will blur the boundaries of the individual steps. Equations 2 show on basis of equation 1 the equilibrium relations for states $p_{\text {eq }}{ }^{*}$ and $p_{\text {eq. }}$.

$\ln \left(\frac{p_{\mathrm{eq}}^{*}}{p^{\circ}}\right)=-\frac{\Delta G_{\mathrm{m}}^{\circ}}{\mathrm{R} T^{*}}$

$\ln \left(\frac{p_{\mathrm{eq}}}{\mathrm{p}^{\circ}}\right)=-\frac{\Delta G_{\mathrm{m}}^{\circ}}{\mathrm{R} T}$

The departure line to the chain of arguments is shown in equation 3: a disturbance $\Delta$ of the baseline equilibrium system (governed by $\Delta G_{\mathrm{m}}{ }^{\circ}$ ) by a non-displaceable excess-to-equilibrium gas amount entails a temperature increase $\Delta T$ after which the system adopts a new stable state; the final temperature of the system is designated $T^{*}$, the baseline temperature is termed $T$.

$\frac{\Delta \Delta G_{\mathrm{m}}^{\circ}}{\mathrm{R}}=\Delta T=T^{*}-T$ 
The energy difference between the two system states in question is for an ideal gas given by the difference of the respective pressures $p_{\text {eq }}{ }^{*}$ and $p_{\text {eq }}$ times the initial molar volume $V_{\text {m }}$; the result is equal to the temperature difference $T^{*}-T=\Delta T$ as equation 4 shows.

$T^{*}-T=\left(\frac{p_{\mathrm{eq}}^{*}}{p_{\mathrm{eq}}}-1\right) \frac{p_{\mathrm{eq}} V_{\mathrm{m}}}{\mathrm{R}}=\left(\frac{p_{\mathrm{eq}}^{*}}{p_{\mathrm{eq}}}-1\right) T=\Delta T$

If the disturbance $\Delta$ of the baseline equilibrium system in equation 3 is expressed as shown in equation 5 , the boundary condition of equation 4 is met.

$\Delta=\frac{\left(\frac{p_{\mathrm{eq}}{ }^{*}}{p_{\mathrm{eq}}}-1\right)}{\ln \left(\frac{\mathrm{p}^{\circ}}{p_{\mathrm{eq}}}\right)} \Rightarrow \frac{\Delta \Delta G_{\mathrm{m}}{ }^{\circ}}{\mathrm{R}}=\Delta T \quad \Rightarrow \quad \frac{\left(\frac{p_{\mathrm{eq}}{ }^{*}}{p_{\mathrm{eq}}}-1\right) \mathrm{R} T}{\Delta G_{\mathrm{m}}{ }^{\circ}} \frac{\Delta G_{\mathrm{m}}{ }^{\circ}}{\mathrm{R}}=\Delta T$

This is the first of four requirements applying: the second relates to the van't Hoff equilibrium pressure scale, it is defined by the difference of equations $2 a$ and $2 b$ as shown in equation 6 .

$\ln \left(\frac{p_{\mathrm{eq}}^{*}}{p^{\circ}}\right)-\ln \left(\frac{p_{\mathrm{eq}}}{p^{\circ}}\right)=\ln \left(\frac{p_{\mathrm{eq}}^{*}}{p_{\mathrm{eq}}}\right)=\frac{\Delta G_{\mathrm{m}}^{\circ}}{\mathrm{R}}\left(\frac{1}{T}-\frac{1}{T^{*}}\right)$

Equation 6 is transformed for the numerator $T^{*}-T=\Delta T$ in the bracketed term and solved for $\Delta G_{\mathrm{m}}{ }^{\circ} / \mathrm{R}$ as equation 7 shows.

$\ln \left(\frac{p_{\mathrm{eq}}{ }^{*}}{p_{\mathrm{eq}}}\right)=\frac{\Delta G_{\mathrm{m}}{ }^{\circ}}{\mathrm{R}}\left(\frac{T^{*}}{T T^{*}}-\frac{T}{T T^{*}}\right)=\frac{\Delta G_{\mathrm{m}}{ }^{\circ}}{\mathrm{R}} \frac{\Delta T}{T T^{*}} \quad \Rightarrow \quad \frac{\Delta G_{\mathrm{m}}^{\circ}}{\mathrm{R}}=\frac{T T^{*}}{\Delta T} \ln \left(\frac{p_{\mathrm{eq}}{ }^{*}}{p_{\mathrm{eq}}}\right)$

Equations 5 and 7 are combined for equation 8.

$\frac{\Delta \Delta G_{\mathrm{m}}^{\circ}}{\mathrm{R}}=\Delta T \Rightarrow \frac{\left(\frac{p_{\mathrm{eq}}{ }^{*}}{p_{\mathrm{eq}}}-1\right)}{\ln \left(\frac{\mathrm{p}^{\circ}}{p_{\mathrm{eq}}}\right)} \frac{\Delta G_{\mathrm{m}}{ }^{\circ}}{\mathrm{R}}=\Delta T \Rightarrow \frac{\left(\frac{p_{\mathrm{eq}}{ }^{*}}{p_{\mathrm{eq}}}-1\right)}{\ln \left(\frac{\mathrm{p}^{\circ}}{p_{\mathrm{eq}}}\right)} \frac{T T^{*}}{\Delta T} \ln \left(\frac{p_{\mathrm{eq}}{ }^{*}}{p_{\mathrm{eq}}}\right)=\Delta T$ 
Equation 8 reveals a quadratic structure, the temperatures product $\left(T^{*} T\right)$ is expressed in terms of equations $2 \mathrm{a}$ and $2 \mathrm{~b}$ which reintroduces $\Delta G_{\mathrm{m}}{ }^{\circ} / \mathrm{R}$ by the square, solving for $\Delta T$ yields equation 9 .

$\frac{\left(\frac{p_{\mathrm{eq}}^{*}}{p_{\mathrm{eq}}}-1\right) \ln \left(\frac{p_{\mathrm{eq}}{ }^{*}}{p_{\mathrm{eq}}}\right)}{\ln \left(\frac{\mathrm{p}^{\circ}}{p_{\mathrm{eq}}}\right) \ln \left(\frac{\mathrm{p}^{\circ}}{p_{\mathrm{eq}}}\right) \ln \left(\frac{\mathrm{p}^{\circ}}{p_{\mathrm{eq}}{ }^{*}}\right)}\left(\frac{\Delta G_{\mathrm{m}}^{\circ}}{\mathrm{R}}\right)^{2}=(\Delta T)^{2} \Rightarrow \Delta T= \pm \frac{\Delta G_{\mathrm{m}}^{\circ}}{\mathrm{R} \ln \left(\frac{\mathrm{p}^{\circ}}{p_{\mathrm{eq}}}\right)} \sqrt{\frac{\left(\frac{p_{\mathrm{eq}}{ }^{*}}{p_{\mathrm{eq}}}-1\right)}{\ln \left(\frac{\mathrm{p}^{\circ}}{p_{\mathrm{eq}}{ }^{*}}\right)} \ln \left(\frac{p_{\mathrm{eq}}{ }^{*}}{p_{\mathrm{eq}}}\right)}$

The third boundary condition is concerned with the question how the excess energy enters the system for which $\Delta G_{\mathrm{m}}{ }^{\circ}$ in equation 9 is understood in a transition state theory (TST) context. Central to TST is the conception of a fast upstream equilibrium between the reactants and an activated complex in which the reaction products are virtually already present; the kinetically measurable reaction event is triggered by a molecular vibration along the reaction coordinate, causing product formation. ${ }^{2}$ This vibration is accounted for by means of a universal frequency factor $k_{B} T / h$ in which $\mathrm{k}_{\mathrm{B}}$ and $\mathrm{h}$ represent the Boltzmann and the Planck constant, respectively. Equation 10 shows the classic Eyring-Polanyi equation connecting the reaction rate $k$ to the molar standard Gibbs enthalpy $\Delta G_{\mathrm{m}}{ }^{\circ}$ which governs the equilibrium between reactants and the activated complex.

$k=\frac{\mathrm{k}_{\mathrm{B}} T}{\mathrm{~h}} \mathrm{e}^{-\Delta G_{\mathrm{m}}^{\circ} / / \mathrm{R} T}$

TST is an ideal building brick in this context because at one hand it relates kinetic causality to molecular vibrations anyway and at the other it is founded on an equilibrium conception, too. However, the activated complex is not a vital entity in this context and drawing that line inside the system is unnecessary: a general $\Delta G_{m}{ }^{\circ}$ indexing of equilibrium context suffices. The causality between system warming and molecular vibration ensues from seeing reaction rate $k$ in $\mathrm{s}^{-1}$ as the frequency $v$ of an IR-active vibrational mode: equation 11 shows these adjustments to equation 10.

$k=v=\frac{\mathrm{k}_{\mathrm{B}} T}{\mathrm{~h}} \mathrm{e}^{-\Delta G_{\mathrm{m}}{ }^{\circ} / \mathrm{R} T} \quad \Rightarrow \quad-T \ln \left(\frac{\mathrm{h} v}{\mathrm{k}_{\mathrm{B}} T}\right)=\frac{\Delta G_{\mathrm{m}}{ }^{\circ}}{\mathrm{R}}$

Equation 11 is inserted into equation 9 as shown in equation 12, temperature $T$ inside the TSTrelated logarithmic term's argument is expressed by the ideal gas as $p_{\text {eq }} V_{m} / R$ which provides via the molar volume an interface to real-gas equations of state; equation 12 is simplified further via $R=$ $\mathrm{N}_{\mathrm{A}} \mathrm{k}_{\mathrm{B}}$ and adjusted for $100 \mathrm{~J}=1 \mathrm{~L}$ bar. 
$\Delta T=(-)( \pm) T \frac{\ln \left(\frac{\mathrm{N}_{\mathrm{A}} \mathrm{h} v}{100 p_{\mathrm{eq}} V_{\mathrm{m}}}\right)}{\ln \left(\frac{\mathrm{p}^{\circ}}{p_{\mathrm{eq}}}\right)} \sqrt{\frac{\left(\frac{p_{\mathrm{eq}}{ }^{*}}{p_{\mathrm{eq}}}-1\right)}{\ln \left(\frac{\mathrm{p}^{\circ}}{p_{\mathrm{eq}}{ }^{*}}\right)} \ln \left(\frac{p_{\mathrm{eq}}^{*}}{p_{\mathrm{eq}}}\right)}$

The negative arithmetic sign on the right of equation 12 is vital: if moved to the left for $-\Delta T$, a negative figure ensues for $-\left(T^{*}-T\right)$ as $T^{*}$ is by definition larger than $T$ and thus only the negative square root is a sensible solution in this context, telling about view direction along the gradient.

The fourth boundary condition takes the approach full circle towards its beginning in equation 3: the matter is all about untangling and solving a linear-logarithmic scaling problem of increments, starting from a $\Delta \Delta$-consideration. However, along the line of argument one $\Delta$-level migrated into the Kelvin temperature scale, equation 12 has actually the meaning of $\Delta \Delta T=\Delta T$ [...] but one $\Delta$-reference on its left is nullified in the event of the other difference taking whereas on the right the $\Delta$-reference has become implicit to the Kelvin-scale. This already anticipates the problem's solution; the left of equation 12 needs by principle no further adaption but $T$ on the right requires a systematic, linear, incremental transformation in order to make the approach work: consequently, thermodynamic temperature $T$ is translated towards the Celsius scale which is shown in equation 13.

$\Delta \vartheta=(T-273.15) \frac{\ln \left(\frac{\mathrm{N}_{\mathrm{A}} \mathrm{h} v}{100 p_{\mathrm{eq}} V_{\mathrm{m}}}\right)}{\ln \left(\frac{\mathrm{p}^{\circ}}{p_{\mathrm{eq}}}\right)} \sqrt{\frac{\left(\frac{p_{\mathrm{eq}}{ }^{*}}{p_{\mathrm{eq}}}-1\right)}{\ln \left(\frac{\mathrm{p}^{\circ}}{p_{\mathrm{eq}}{ }^{*}}\right)} \ln \left(\frac{p_{\mathrm{eq}}}{p_{\mathrm{eq}}}\right)}$

Equation 13 represents an ideal expression of the system temperature differences caused by extraequilibrial atmospheric concentration changes of a greenhouse gas. The model determines on basis of the gradient between the system's initial equilibrium state at pressure $p_{\text {eq }}$ and the higher final equilibrium pressure $p_{\mathrm{eq}}{ }^{*}$ the energy flux towards the system, in terms of $h v$ and with regard to the initial inner energy $p_{\text {eq }} V_{m}$ via a TST-influenced rationale. The energy excess manifests by the ideal gas law in a temperature increase $\Delta \vartheta$; by conception, there is a separation into two sub-systems, the heat absorbing $p_{\text {eq }}$ baseline system and the heating system bound to pressure margin $p_{\text {eq }}{ }^{*}-p_{\text {eq }}$ : because of the $0^{\text {th }}$ law of thermodynamics, heat transfer will occur as long a temperature gradient between these sub-systems exists, an argument extending further to any sub-system in thermal contact (e.g. the balance atmosphere). Since this model essentially represents an ideal energy balance drawing, the $\Delta \vartheta$ contributions obtained for the individual vibrational modes are additively related and externalities such as clouds, sun activity or radiative heat dissipation into space are of no conceptual concern as the model lacks a transient element: the molecular vibrations radiate energy regardless of circumstance until the system temperature for equilibrium pressure $p_{\mathrm{eq}}{ }^{*}$ is reached. 


\section{Results}

Equation 13 is calibrated to a pre-industrial baseline marked by the year 1700 on basis of data from https://www.co2levels.org/ and https://www.temperaturerecord.org/; footage of the sources (e.g. the U.S. National Oceanographic and Atmospheric Administration) is available as electronic supplementary information (ESI). Global atmospheric $\mathrm{CO}_{2}$-concentration is given with $276.7 \mathrm{ppm}$, global average temperature with $13.18^{\circ} \mathrm{C}$, defined in relation to April 2021: supposedly, 1700 was $1.31^{\circ} \mathrm{C}$ cooler (temperature anomaly $-0.57^{\circ} \mathrm{C}$ ) than global April 2021 temperature which was 0.79 ${ }^{\circ} \mathrm{C}$ warmer than the global $20^{\text {th }}$ century average of $13.7^{\circ} \mathrm{C} .{ }^{3}$ Equation 14 shows the resulting baseline parameters to equation 13 , for molar volume calculation the van der Waals equation is used but pressure is considered as ideal in the $10^{-4}$ to $10^{-2}$ bar domain.

$p_{\text {eq }}=0.0002767$ bar; $V_{\mathrm{m}}(\mathrm{vdW})=86038.196 \mathrm{~L} \mathrm{~mol}^{-1} ; p_{\text {eq }} V_{\mathrm{m}}=23.807 \mathrm{~L} \mathrm{bar} \mathrm{mol}^{-1} ; \vartheta_{\text {eq }}=13.18^{\circ} \mathrm{C}$

The well-known IR-active vibrational modes of carbon dioxide are shown in table 1, along the value of the TST-related logarithmic term they affect.

Table 1 IR-active vibrational modes of carbon dioxide and the corresponding value of the TST-related term in equation 13.

\begin{tabular}{|l|c|c|c|}
\hline $\mathrm{CO}_{2}$-vibrational mode & Wave number & Frequency $\boldsymbol{v}$ & $\ln \left(\frac{\mathbf{N}_{\mathrm{A}} \mathbf{h} \boldsymbol{v}}{\mathbf{1 0 0} \boldsymbol{p}_{\text {eq }} \boldsymbol{V}_{\mathrm{m}}}\right)$ \\
\hline $\mathrm{C}=\mathbf{O}$ asymmetric stretching & $2349 \mathrm{~cm}^{-1}$ & $70.42125 \cdot 10^{12} \mathrm{~Hz}$ & 2.46849 \\
\hline $\mathbf{O}=\mathrm{C}=\mathbf{O}$ bending (twofold degenerate) & $667 \mathrm{~cm}^{-1}$ & $19.99616 \cdot 10^{12} \mathrm{~Hz}$ & 1.20943 \\
\hline
\end{tabular}

The Greenhouse effect of excess $\mathrm{CO}_{2}$-emissions is assessed for eight data points ranging from 1880 to April 2021 as shown in table 2; the data values and their if need be condensing into monthly or annual mean values are available as ESI.

Table 2 Assessment of global mean temperatures on basis of equations 13 and their comparison to publicly available data.

\begin{tabular}{|c|c|c|c|c|c|c|c|c|}
\hline $\begin{array}{l}1700 \text { baseline } \\
276.7 \mathrm{ppm} \\
13.18^{\circ} \mathrm{C} \\
\end{array}$ & $\begin{array}{c}\Delta \vartheta\left[{ }^{\circ} \mathrm{C}\right] \\
290.7 \mathrm{ppm} \\
1880 \\
\end{array}$ & $\begin{array}{c}\Delta \vartheta\left[{ }^{\circ} \mathrm{C}\right] \\
296.1 \mathrm{ppm} \\
1901 \\
\end{array}$ & $\begin{array}{c}\Delta \vartheta\left[{ }^{\circ} \mathrm{C}\right] \\
305.0 \mathrm{ppm} \\
1925 \\
\end{array}$ & $\begin{array}{c}\Delta \vartheta\left[{ }^{\circ} \mathrm{C}\right] \\
310.7 \mathrm{ppm} \\
1950 \\
\end{array}$ & $\begin{array}{c}\Delta \vartheta\left[{ }^{\circ} \mathrm{C}\right] \\
330.3 \mathrm{ppm} \\
\operatorname{Jan} 1975 \\
\end{array}$ & $\begin{array}{c}\Delta \vartheta\left[{ }^{\circ} \mathrm{C}\right] \\
370.3 \mathrm{ppm} \\
\text { Jan } 2001 \\
\end{array}$ & $\begin{array}{c}\Delta \vartheta\left[{ }^{\circ} \mathrm{C}\right] \\
391.1 \mathrm{ppm} \\
\operatorname{Jan} 2011 \\
\end{array}$ & $\begin{array}{c}\Delta \vartheta\left[{ }^{\circ} \mathrm{C}\right] \\
416.2 \mathrm{ppm} \\
\text { Apr } 2021 \\
\end{array}$ \\
\hline $\begin{array}{l}\mathrm{C}=\mathrm{O} \text { asymmetric } \\
\text { stretching }\end{array}$ & 0.06955 & 0.09603 & 0.13929 & 0.16675 & 0.25978 & 0.44355 & 0.53623 & 0.64573 \\
\hline $\mathrm{O}=\mathrm{C}=\mathrm{O}$ bending 1 & 0.03407 & 0.04705 & 0.06825 & 0.08170 & 0.12728 & 0.21732 & 0.26272 & 0.31637 \\
\hline $\mathrm{O}=\mathrm{C}=\mathrm{O}$ bending 2 & 0.03407 & 0.04705 & 0.06825 & 0.08170 & 0.12728 & 0.21732 & 0.26272 & 0.31637 \\
\hline$\Sigma \Delta \vartheta\left[{ }^{\circ} \mathrm{C}\right]$ & +0.138 & +0.190 & +0.276 & +0.330 & +0.514 & +0.878 & +1.062 & +1.278 \\
\hline$\Sigma \Delta \vartheta\left[{ }^{\circ} \mathrm{C}\right]+13.18^{\circ} \mathrm{C}$ & 13.32 & 13.37 & 13.46 & 13.51 & 13.69 & 14.06 & 14.24 & 14.46 \\
\hline $\begin{array}{l}\text { Temperature by } \\
\text { data }\left[{ }^{\circ} \mathrm{C}\right]\end{array}$ & 13.58 & 13.59 & 13.52 & 13.57 & 13.86 & 14.21 & 14.27 & 14.49 \\
\hline $\begin{array}{l}\text { Deviation of model } \\
\text { (1700 baseline) } \\
\text { from data }\end{array}$ & $-1.9 \%$ & $-1.6 \%$ & $-0.4 \%$ & $-0.4 \%$ & $-1.2 \%$ & $-1.1 \%$ & $-0.2 \%$ & $-0.2 \%$ \\
\hline $\begin{array}{l}\text { Deviation of model } \\
\text { (1880 baseline) } \\
\text { from data }\end{array}$ & $0 \%$ & $+0.3 \%$ & $+1.5 \%$ & $+1.5 \%$ & $+0.7 \%$ & $+0.8 \%$ & $+1.7 \%$ & $+1.7 \%$ \\
\hline
\end{tabular}


Table 2 shows that the model predicts within a $\pm 2 \%$ margin and for illustration purposes, the relative deviation of the model is given if 1880 were adopted as baseline year in lieu of 1700 . This is because 1700 pre-dates the advent of regular temperature measurements (from 1880 onwards) and the 1880 value represents those with the most pronounced deviation. However, in both cases the deviation is discernibly less than $\pm 2 \%$ and it is explicitly stated that the data points were merely chosen for a subjective impression of appropriate coverage under constraints.

The global mean temperatures at generic $\mathrm{CO}_{2}$-levels are extrapolated for eight values between 450 ppm and $7000 \mathrm{ppm}$; the latter value is for an idea about the impact of the $7832 \mathrm{ppm} \pm 1676 \mathrm{ppm}$ concentration reported by RETALLACK as peak value during the Permian-Triassic mass extinction event; ${ }^{4-6}$ table 3 shows the figures.

Table 3 Global mean temperatures extrapolated on basis of equation 13 for generic atmospheric $\mathrm{CO}_{2}$-concentrations.

\begin{tabular}{|l|c|c|c|c|c|c|c|c|}
\hline $\begin{array}{l}1700 \text { baseline } \\
276.7 \mathrm{ppm} \\
13.18{ }^{\circ} \mathrm{C}\end{array}$ & $\begin{array}{c}\Delta \vartheta\left[{ }^{\circ} \mathrm{C}\right] \\
450 \mathrm{ppm}\end{array}$ & $\begin{array}{c}\Delta \vartheta\left[{ }^{\circ} \mathrm{C}\right] \\
580 \mathrm{ppm}\end{array}$ & $\begin{array}{c}\Delta \vartheta\left[{ }^{\circ} \mathrm{C}\right] \\
750 \mathrm{ppm}\end{array}$ & $\begin{array}{c}\Delta \vartheta\left[{ }^{\circ} \mathrm{C}\right] \\
1200 \mathrm{ppm}\end{array}$ & $\begin{array}{c}\Delta \vartheta\left[{ }^{\circ} \mathrm{C}\right] \\
2000 \mathrm{ppm}\end{array}$ & $\begin{array}{c}\Delta \vartheta\left[{ }^{\circ} \mathrm{C}\right] \\
3000 \mathrm{ppm}\end{array}$ & $\begin{array}{c}\Delta \vartheta\left[{ }^{\circ} \mathrm{C}\right] \\
4500 \mathrm{ppm}\end{array}$ & $\begin{array}{c}\Delta \vartheta[000 \mathrm{ppm} \\
7000\end{array}$ \\
\hline $\begin{array}{l}\mathrm{C}=\mathrm{O} \text { asymmetric } \\
\text { stretching }\end{array}$ & 0.81946 & 1.35995 & 2.00683 & 3.51673 & 5.80331 & 8.28296 & 11.56884 & 16.68558 \\
\hline $\mathrm{O}=\mathrm{C}=\mathrm{O}$ bending 1 & 0.40149 & 0.66630 & 0.98324 & 1.72302 & 2.84332 & 4.05821 & 5.66812 & 8.17506 \\
\hline $\mathrm{O}=\mathrm{C}=\mathrm{O}$ bending 2 & 0.40149 & 0.66630 & 0.98324 & 1.72302 & 2.84332 & 4.05821 & 5.66812 & 8.17506 \\
\hline$\Sigma \Delta \vartheta\left[{ }^{\circ} \mathrm{C}\right]$ & +1.662 & +2.693 & +3.973 & +6.963 & +11.490 & +16.399 & +22.905 & +33.036 \\
\hline$\Sigma \Delta \vartheta\left[{ }^{\circ} \mathrm{C}\right]+13.18^{\circ} \mathrm{C}$ & 14.84 & 15.87 & 17.15 & 20.14 & 24.67 & 29.58 & 36.09 & 46.22 \\
\hline$\frac{\Delta \Delta \vartheta\left[{ }^{\circ} \mathrm{C}\right]}{\Delta[\mathrm{ppm}]}$ & $\leftarrow$ & 0.00793 & 0.00753 & 0.00644 & 0.00566 & 0.00491 & 0.00434 & 0.00405 \\
\hline
\end{tabular}

Table 3 lists for $7000 \mathrm{ppm}$ atmospheric $\mathrm{CO}_{2}$-concentration a global mean temperature of $46{ }^{\circ} \mathrm{C}$ which appears reasonable enough in context of the Permian-Triassic mass extinction event. Table 3 shows further that the speed of global warming somewhat decelerates with increasing concentration level. The data of table 3 are fitted for an empiric expression of global average temperature $\vartheta_{\mathrm{g}}$ in relation to atmospheric $\mathrm{CO}_{2}$-concentration, yielding the polynomial expression of equation $15\left(R^{2}=0.99995\right)$.

$\vartheta_{\mathrm{g}}\left[{ }^{\circ} \mathrm{C}\right]=\left(5.26823 \cdot 10^{-11}[\mathrm{ppm}]^{3}-8.01305 \cdot 10^{-7}[\mathrm{ppm}]^{2}+7.98795 \cdot 10^{-3}[\mathrm{ppm}]+11.5069\right)\left[{ }^{\circ} \mathrm{C}\right]$

\section{Discussion}

The virtual agreement between the figures obtained from this ideal $\mathrm{CO}_{2}$-based $\mathrm{Greenhouse} \mathrm{effect}$ rationale and publicly available data is unsettling and one can just point rather dumbfounded at the clear presuppositions and the transparent line of argument. The data are beyond influence which supports the claim of objectivity.

Even if equation 13 were taken for a mere coincidental empiric expression, it still would shine as a tool of precision and accuracy, all the more with view to its general significance towards greenhouse gases and resource-efficient origin. However, there is no reason in seeing the outcomes of this work in terms of coincidence except for the evident fact that an ideal energy balance drawing does 
reproduce actual data reality: that is because for a solely radiative process it can be expected that about half or at least a substantial proportion of the energy surplus should dissipate into space.

Since the ideal model arrives at virtually no hint of an energy loss on basis of real data, it must figure quite concisely to the culminated sum of all related externalities such as the other greenhouse gases and the processes of the atmospheric water- $\mathrm{CO}_{2}$ system: ${ }^{7,8}$ only that can reasonably explain why carbon dioxide appears as the solely effective ideal measure of anthropogenic climate change, which entails the conclusion that the externalities in question must effectively scale in proportion.

The atmospheric water- $\mathrm{CO}_{2}$ system appears of vital contextual importance to this explanation, notably ARRHENIUS pointed its significance to climate processes out first in 1897. ${ }^{9,10}$ Recently, SCHNEIDER et al assessed that at atmospheric $\mathrm{CO}_{2}$-levels of $1200 \mathrm{ppm}$ or more stratocumulus clouds become instable, ${ }^{11}$ entailing further warming. For that work the value of $1200 \mathrm{ppm}\left(20.14^{\circ} \mathrm{C}\right)$ is actually included in table 3 and it gives a principal idea of how the excess energy brought into the atmosphere via the $\mathrm{CO}_{2}$-Greenhouse effect relates further to phase change respective mass transfer processes; yet such matters outreach by far the scope of this paper which arrived at its conclusion.

\section{Conclusion}

The causality of preceding atmospheric excess-to-equilibrium $\mathrm{CO}_{2}$-amounts and subsequent system temperature increase can be demonstrated on basis of ideal physical chemistry fundamentals. The model reproduces publicly available data from 1880 to 2021 at less than $\pm 2 \%$ deviation and enables extrapolation towards future global mean temperature values. The ideal nature of the model allows easy adaption for other greenhouse gases and may serve as reference for conclusions about the energetic weighting and wider role of the $\mathrm{CO}_{2}$-based proportion in the total Greenhouse effect.

\section{Conflicts of interest}

No conflicts to declare.

\section{References}

1 R. S. Kandel, in Carbon Dioxide, eds. W. Bach, A. J. Crane, A. L. Berger and A. Longhetto, Springer Netherlands, Dordrecht, 1983, pp. 179-218.

2 P. Ptáček, F. Šoukal and T. Opravil, in Introducing the Effective Mass of Activated Complex and the Discussion on the Wave Function of this Instanton, eds. P. Ptáček, T. Opravil and F. Šoukal, InTech, 2018.

3 NOAA National Centers for Environmental Information, State of the Climate: Global Climate Report for April 2021, published online May 2021, retrieved on June 8, 2021 from https://www.ncdc.noaa.gov/sotc/global/202104.

4 G. J. Retallack, Gondwana Res., 2013, 24, 90-103.

5 M. J. Benton and A. J. Newell, Gondwana Res., 2014, 25, 1308-1337.

6 M. J. Benton and R. J. Twitchett, Trends Ecol. Evol., 2003, 18, 358-365.

7 I. S. A. Isaksen, C. Granier, G. Myhre, T. Berntsen, S. B. Dalsøren, M. Gauss, Z. Klimont, R. Benestad, P. Bousquet, W. Collins, T. Cox, V. Eyring, D. Fowler, S. Fuzzi, P. Jöckel, P. Laj, U. Lohmann, M. Maione, P. Monks, A. S. H. Prevot, F. Raes, A. Richter, B. Rognerud, M. Schulz, D. Shindell, D. Stevenson, T. Storelvmo, W.-C. Wang, M. van Weele, M. Wild and D.

J. Wuebbles, in The Future of the World's Climate, Elsevier, 2012, pp. 309-365.

8 K. H. Rosenlof, in Encyclopedia of Atmospheric Sciences, Elsevier, 2015, pp. 250-256.

9 S. Arrhenius, Publ. Astron. Soc. Pac., 1897, 9, 14.

10 W. Stannard, Nat. Sci., 2018, 10, 1-10.

11 T. Schneider, C. M. Kaul and K. G. Pressel, Nat. Geosci., 2019, 12, 163-167. 